\title{
Challenges and Their Practices in Adoption of Hybrid Cloud Computing: An Analytical Hierarchy Approach
}

\author{
Siffat Ullah Khan $\mathbb{D}^{1},{ }^{1}$ Habib Ullah Khan $\mathbb{D}^{2}{ }^{2}$ Naeem Ullah, ${ }^{1}$ and Rafiq Ahmad Khan $\mathbb{D}^{1}$ \\ ${ }^{1}$ Software Engineering Research Group (SERGUOM), Department of Computer Science \& IT, University of Malakand, Chakdara, \\ Khyber Pakhtunkhwa, Pakistan \\ ${ }^{2}$ Department of Accounting and Information Systems, College of Business and Economics, Qatar University, Doha, Qatar \\ Correspondence should be addressed to Habib Ullah Khan; habib.khan@qu.edu.qa
}

Received 4 July 2021; Accepted 16 August 2021; Published 3 September 2021

Academic Editor: Chien Ming Chen

Copyright (C) 2021 Siffat Ullah Khan et al. This is an open access article distributed under the Creative Commons Attribution License, which permits unrestricted use, distribution, and reproduction in any medium, provided the original work is properly cited.

\begin{abstract}
Cloud computing adoption provides various advantages for companies. In particular, hybrid cloud shares the advantages of both the public and private cloud technologies because it combines the private in-house cloud with the public on-demand cloud. In order to obtain benefits from the opportunities provided by the hybrid cloud, organizations want to adopt or develop novel capabilities. Maturity models have proved to be an exceptional and easily available method for evaluating and improving capabilities. However, there is a dire need for a robust framework that helps client organizations in the adoption and assessment of hybrid cloud. Therefore, this research paper aims to present a taxonomy of the challenging factors faced by client organizations in the adoption of hybrid cloud. Typically, such a taxonomy is presented on the basis of obtained results from the empirical analysis with the execution of analytical hierarchy process (AHP) method. From the review of literature and empirical study, in total 13 challenging factors are recognized and plotted into four groups: "Lack of Inclination," "Lack of Readiness," "Lack of Adoption," and "Lack of Satisfaction." The AHP technique is executed to prioritize the identified factors and their groups. By this way, we found that "Lack of Adoption" and "Lack of Satisfaction" are the most significant groups from the identified challenging factors. Findings from AHP also show that "public cloud security concern" and "achieving QoS" are the upper ranking factors confronted in the adoption of hybrid cloud mechanism by client organizations because their global weight $(0.201)$ is greater than those of all the other reported challenging factors. We also found out 46 practices to address the identified challenges. The taxonomy developed in this study offers a comprehensive structure for dealing with hybrid cloud computing issues, which is essential for the success and advancement of client and vendor organizations in hybrid cloud computing relationships.
\end{abstract}

\section{Introduction}

Recently, the cloud computing mechanism has grown up very rapidly, and it has many unique features like elasticity, pooling of a resource, on-demand support, and wide network access $[1,2]$. Technology-assisted learning is becoming more common, with most educational institutions across the globe using learning management systems, content management systems, virtual networks, and virtual machines to enhance student learning [3]. In this day and age, educational institutions are even using private clouds to improve the student experience [3]. Cloud computing acquires some of the features of cluster computing, distributed computing, and grid computing but still has its unique features $[4,5]$. "Users of a cloud service only use the volume of IT resources they need, and only pay for the volume of IT resources they use" [6]. In the field of IT, cloud computing brings revolution and provides different concepts from the traditional IT environment [7]. Many organizations of all sizes (small, medium, and large) have adopted and are spending on cloud computing-related techniques [8]. SMEs embrace cloud computing because it cost-effectively provides IT resources [9]. Cloud infrastructure implementation models include the public cloud, private cloud, hybrid cloud, and community cloud [10]. Typically, the service model of the cloud consists of "software as a service" (SaaS), "platform as a 
service" (PaaS), and "infrastructure as a service" (IaaS) [9]. The decision as to which model is suitable to be adopted for a particular organization depends on various factors. "Hybrid cloud deployment model has proved more significant, both in terms of better economic aspects and business agility" $[11,12]$. National Institute of Standards and Technology (NIST) defines hybrid cloud as "a combination of public and private clouds bound together by either standardized or proprietary technology that enables data and application portability." The adoption of new technology requires many changes within the organization $[13,14]$.

The traditional cloud computing task offloading algorithm consumes abundant energy in task scheduling, which results in a longer average task waiting time [15]. For this reason, a cloud computing task offloading algorithm based on dynamic multiobjective evolution is proposed by the authors of [15]. In order to ensure the parallel completion of multiple tasks, the dynamic multiobjective evolution method is used to construct the cloud computing task scheduling model and complete the cloud computing task scheduling [15]. Then, based on the calculated effectiveness and validity of energy consumption to complete the initial operation distribution and offloading priority, the time and cost of task offloading are calculated according to the raking results of task offloading priority. The cloud computing tasks are distributed with minimum time and minimum cost as the goal. Hamouda et al. [16] proposed a reconfigurable formal model of the hybrid cloud architecture, and then they utilized instantiations of this model, simulation, and real-time execution runs to estimate different performance metrics related to fault detection and self-recovery strategies in hybrid cloud.

Literature reveals that theories and models developed by scholars are mainly focusing on such factors that affect technology acceptance [17]. This is the extended version of our previous study [18]. In this paper, we review the latest work performed in the field of hybrid cloud computing and recognize the various challenging factors faced by client organizations during the adoption of cloud computing. For these challenges, we also find practices. The primary research questions that are answered in this paper are the following:

RQ1: What are the challenging factors to be avoided by client organizations in adopting hybrid cloud computing, as identified in the literature and industrial survey?

RQ2: How could the defined challenging variables be prioritized via AHP strategy?

RQ3: What are the practices to be adopted by vendor organizations to develop effective relationships with client organizations in the adoption of hybrid cloud mechanism, as described in the literature and industrial survey?

RQ4: What would be the taxonomy for the identified factors that could assist the stakeholders (clients and vendors) in developing an efficient partnership between each other in such a domain?

This paper is organized as follows: Section 2 provides a background to cloud computing. The research process and methodology are described in Section 3. In Section 4, findings from the SLR, empirical study, and analytical hierarchy process (AHP) approach are presented and analyzed. In Section 5, discussion of the study is presented. The research description is provided in Section 6. Section 7 explains the limitation of the research, followed by the conclusion and future work in Section 8.

\section{Materials and Methods}

Cloud computing emerges as the fifth generation of computing which brings a revolution in the way of computation. "Cloud computing doesn't limit to the grid, parallel, and distributed computing but it involves the power of such paradigms at any level to form a resource pool" [19]. Various stakeholders, such as clients, developers, engineers, executives, academicians, and architects, define cloud computing differently [20]. "Cloud computing is a model for enabling ubiquitous, convenient, on-demand network access to a shared pool of configurable computing resources (e.g., networks, servers, storage, applications, and services) that can be rapidly provisioned and released with minimal management effort or service provider interaction" [21] . Gartner in [22] defines "Cloud computing is a style of computing where massively scalable IT-related capabilities are provided as a service across the Internet to multiple external customers." Forrester's [23] said that "cloud computing is a standardized IT capability (services, software, or infrastructure) delivered via Internet technologies in a pay-per-use, self-service way."

2.1. Cloud Computing Service Model. In the software industry, big players such as Microsoft, as well as other Internet technology heavyweights, including Google and Amazon, are adding the development of cloud services.

Software as a service (SaaS), platform as a service (PaaS), and infrastructure as a service (IaaS) are the three preliminary types of cloud computing services. "In SaaS computer applications are accessed over the Internet rather than being installed on a local computing device or in a local data center" [24]. Desk Away, Dropbox, SkyDrive (Windows Live), Mozy, Google Docs, Pixlr, Zoho Invoice, and CRM on-demand are some of the well-known SaaS examples. PaaS offers an online platform for the creation and operation of applications by software developers [6]. Force.com, Microsoft Windows Azure, and Google App Engine are some examples of PaaS. IaaS works as a cloud provider for hardware such as storage, network, and server and other relevant software such as OS, file system, and virtualization technologies as a service [25]. Joyent, EC2, Zimory, ElasticHosts, Amazon, S3, Rackspace, and GoGrid are examples of IaaS service providers.

2.2. Cloud Computing Deployment Model. In different types of delivery models, cloud computing services and technologies are deployed based on their characteristics and intent, as well as the distinction between user classes [26]. Public, private, community, and hybrid cloud are the cloud deployment types. 
A public cloud is one in which the cloud infrastructure and computational services are made accessible over the Internet to the general type public. It is operated and managed by a cloud company that provides customers with cloud services.

A private or internal cloud is one in which a single entity manages the cloud infrastructure and computing environment exclusively. It may be operated by a company or a third-party and may be held within or outside the data center of the organization. A private cloud has the ability to give the enterprise greater control than a public cloud over the infrastructure, computing resources, and cloud customers.

A community cloud is shared and serves a particular community through many organizations. It is to some extent similar to the private cloud, except in a single entity; the technology and computing services are restricted to more than two organizations with shared privacy, protection, and regulatory considerations.

Hybrid clouds are more complex than the other deployment models, and they are a combination of public and private clouds bound together by either standardized or proprietary technology that enables data and application portability [21].

2.3. Hybrid Cloud Related Work. Majority of the current research is shedding light on different aspects of hybrid cloud. For example, Ristova et al. [27] discuss hybrid cloud and its utilization in the midmarket and propose a method for mass customization and its association in clouds environment. Khadilkar et al. [28] propose a solution for data security and regulatory in using hybrid cloud computing environment. Amrohi and Khadilkar [29] state that organizations utilizing hybrid cloud can take advantage of both the public cloud and private cloud. Heckel [30] provides some of the basic ideas of cloud computing and also discusses the technological requirements for establishing a hybrid cloud environment. Nepalp et al. [31] provide a solution for secure data storage in the hybrid cloud deployment. According to Javadi et al. [32], "a scalable hybrid cloud infrastructure as well as resource provisioning policies assure QoS targets of the users." Tanimotoet et al. [33], propose an enterprise data management method for a hybrid cloud configuration. According to Judith et al. [34], "if a few developers in a company use a public cloud service to prototype a new application that is completely disconnected from the private cloud or the data center, the company does not have a hybrid environment, but if a company uses a public development platform that sends data to a private cloud or a data center-based application, the cloud is hybrid."

According to Weinman [35], "under the right conditions, hybrid clouds can optimize costs while still exploiting the benefits of public clouds such as geographic dispersion and business agility."

A cloud-based security company (Trend Micro) indicated via an empirical survey that the "public cloud services fail to meet the IT and business requirements of some of the business organizations." Alternatively, the "safer option," private cloud, requires significant infrastructure and operations development along with new skill sets required by its IT staff. Although there are ways of balancing each of these concerns, this will ultimately lead to a hybrid of these environments, along with an array of other noncloud environments.

Khan and Ullah [18] "surveyed storage and server decision-makers at North American, Asian Pacific, and European enterprises and found that various hybrid cloud implementations were the preferred approach."

\section{Research Methodology}

The proposed research methodology is presented in Figure 1 and consists of the following three phases.

3.1. SLR Conduction Stage 1: identifying challenges faced by client organizations and their practices in adoption of hybrid cloud computing.

In stage 1, two systematic literature reviews (SLRs) were conducted to extract the relevant data: one for the purpose of identifying the challenges faced by client organizations in the adoption of hybrid cloud computing $[18,36]$ and another to identify practical solutions for these challenges. We followed the SLR approach because SLR is a different method from an ordinary conducted literature review, and it requires more time as well as effort to complete [37-39]. We studied several SLRs [37-39] for guidance. We initially developed the SLR protocol, which was validated and has been published [36]. The SLR1 protocol was then implemented, and the findings of the SLR1 have been published [18]. Through the SLR1, we have identified 12 challenges in such a domain. Among these challenges, 8 were considered critical challenges on the basis of their high frequency. For these critical challenges, we then conducted SLR2 and found out 46 practices out of a sample of 90 papers.

3.2. Empirical Study Conduction Stage 2: validating the findings of SLR and finding out new challenges faced by client organizations and their practices in adoption of hybrid cloud computing.

In stage 2, a survey of 42 hybrid cloud computing experts was conducted to verify the results of SLRs and to recognize other significant challenges and their practices. An empirical survey refers to the experimental research which gathers data based on qualitative and quantitative description from a sample of population [35]. In the collection of implicit data for an issue, empirical survey is the most commonly used tool [40]. A similar approach was followed by other researchers [41-43].

3.3. Application of AHP Stage 3: prioritizing the identified challenges with their respective categories.

For the purpose of prioritizing the listed challenges and their corresponding categories, the analytical hierarchy process (AHP) approach is used. AHP was developed by Saaty [44] and is a popular classical multiple-criteria 
Step 1: Identification of Challenges and its Practices in the Adoption of Hybrid Cloud Computing from Clients Perspectives

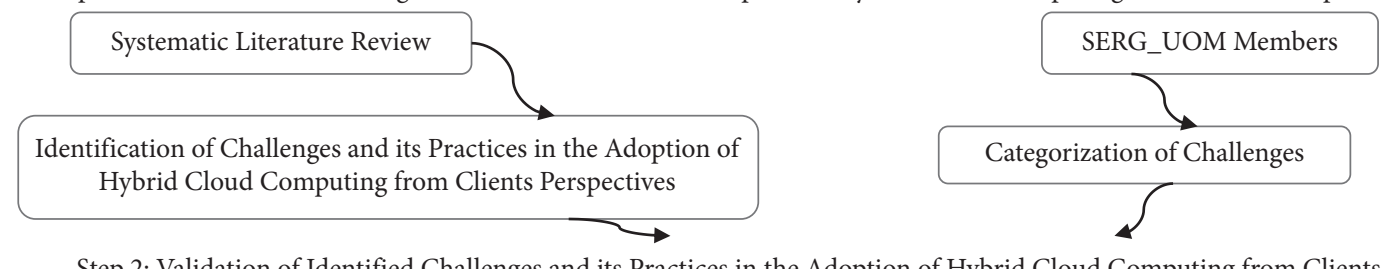

Step 2: Validation of Identified Challenges and its Practices in the Adoption of Hybrid Cloud Computing from Clients Perspectives

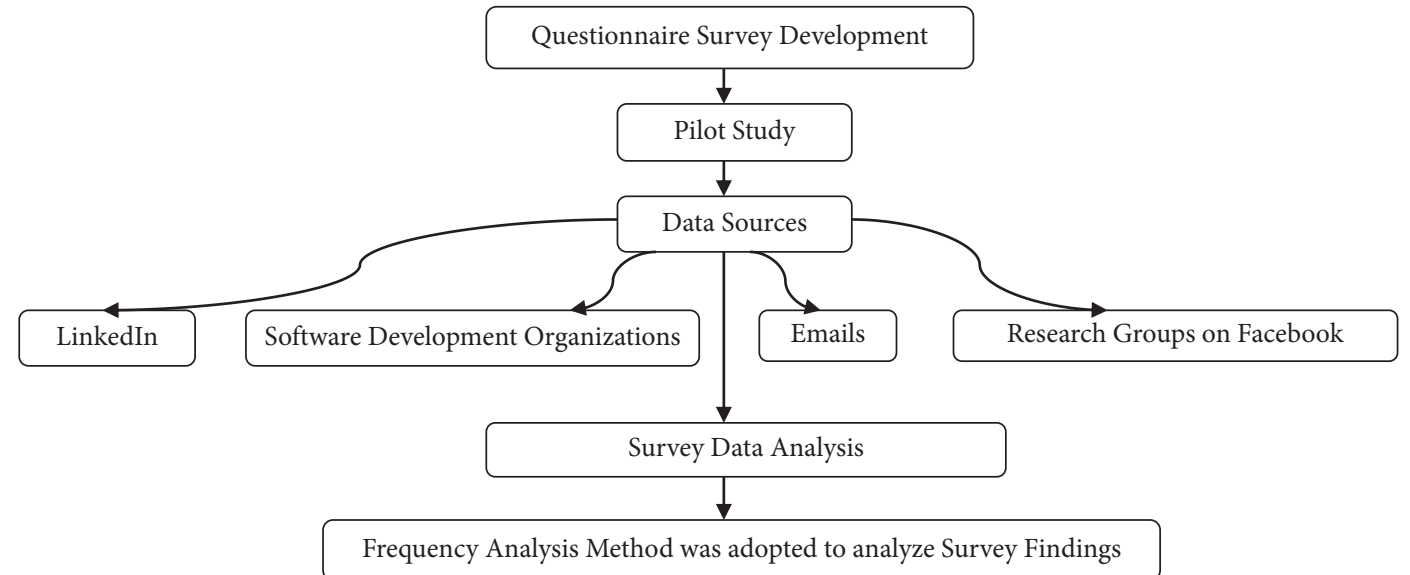

Step 3: Application of Analytical Hierarchy Process (AHP)

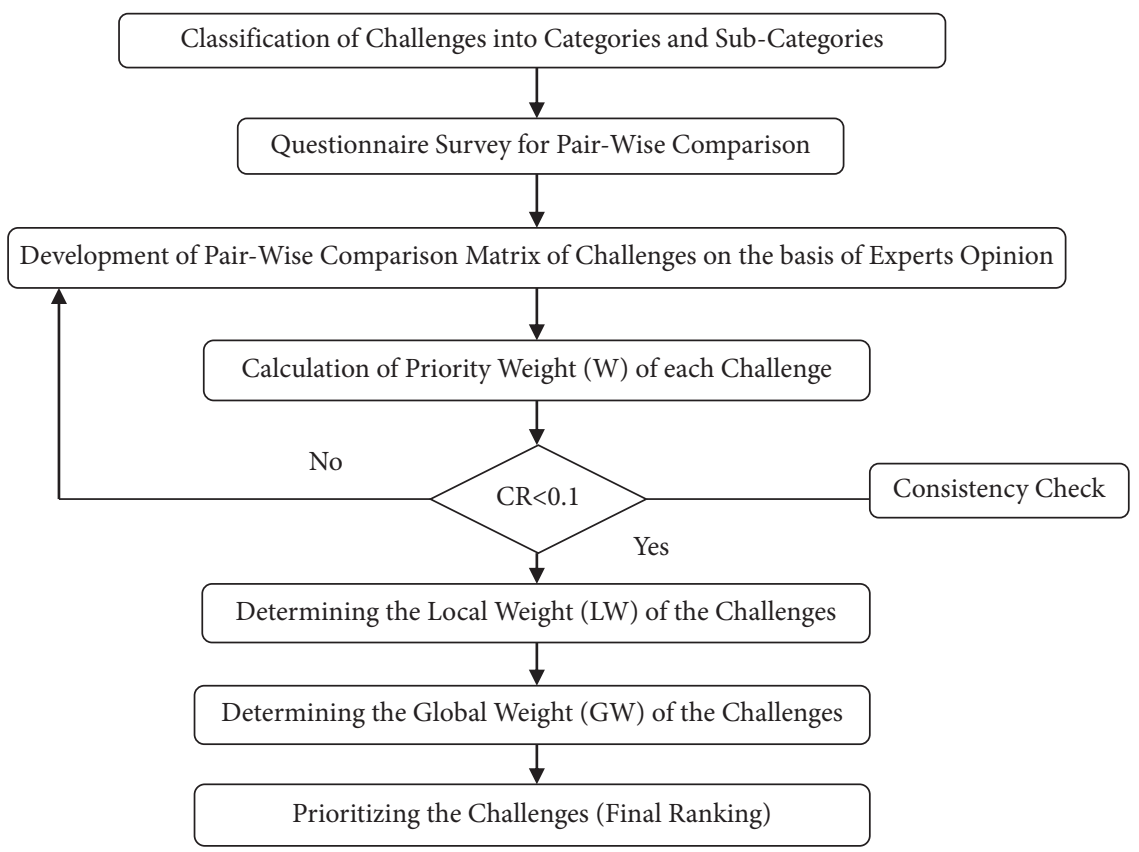

FIGURE 1: Research methodology.

decision-making (MCDM) method. Typically, such an approach of ranking and prioritizing given variables is accurate and precise. The main aim of such a study is to give rank and to prioritize the hybrid cloud computing challenges faced by client organizations. Classical AHP is therefore ideally suited for the study of the data obtained using the form of the survey. In addition, such a technique (AHP) has previously been utilized to cope with complex decision-making issues in numerous other research areas. In Figure 2, the steps for the application of AHP are presented. AHP's three major stages are as follows.

3.3.1. Decomposition of a Complex Decision Problem to a Simple Hierarchy Structure. Here, the problem of decision making is decomposed into related elements of decision making $[45,46]$. At least three levels are used to divide the hierarchical structure of the question: at level 1, the goal of 


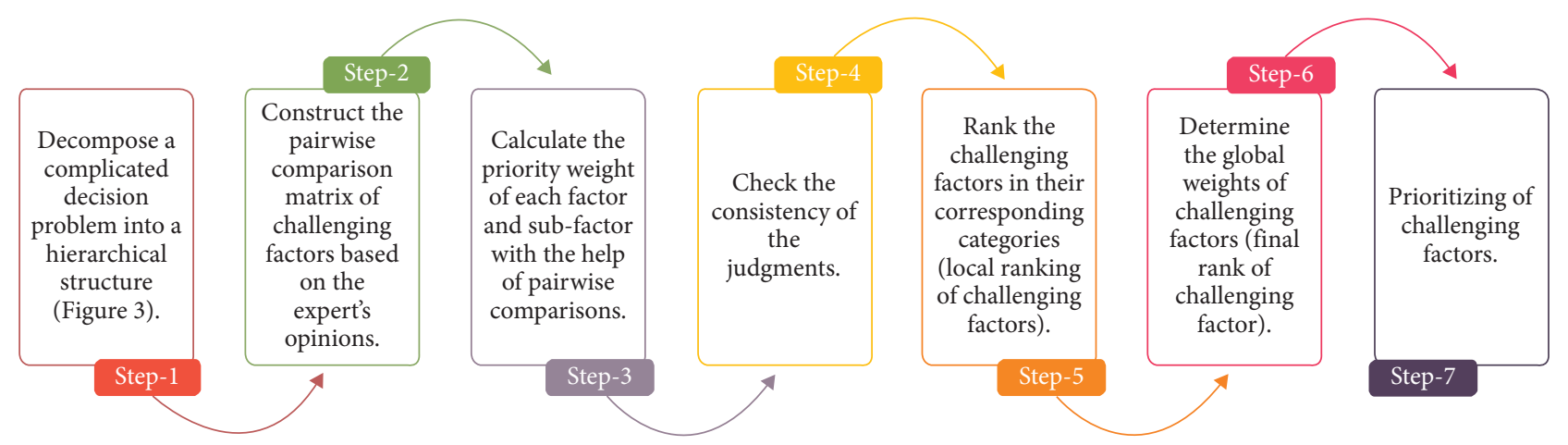

FIGURE 2: Phases of AHP.

the problem is presented; level 2 gives the challenges; similarly, subchallenges are presented at level 3 as depicted in Figure 3.

3.3.2. Survey Regarding the Pairwise Comparison. In order to incorporate the aforementioned AHP approach of prioritization and corresponding categorization of challenges, we conducted a survey with the senior members of the Software Engineering Research Group, University of Malakand (SERGUOM). In total, 8 respondents gave positive feedback, and so they were included to take part in the second phase of questionnaire survey.

The Supplementary Material provides the questionnaire of the second survey sample. The data obtained from 8 participants in the survey and this small sample may threaten the later results of this study; however, the AHP is a subjective methodology and may consider small sample of data also [45, 46]. Other researchers [47-51] with relatively small sample sizes have adopted a similar strategy.

3.3.3. Pairwise Comparisons. To calculate the priority weights of the identified challenges, pairwise comparison of these challenges was conducted. At each level, comparison of these challenges was performed based on their degree of impact and, also, based on the criteria specified at upper level [52]. For instance, the matrix-comparison criteria, i.e., [C] $=$ $\{\mathrm{Cx} \mid x=1,2, \ldots, n\}$, was used, where $n$ is the evaluation matrix A, i.e., $x y(y, x=1,2, \ldots, n)$, which presents the normalized relative weight as shown in equation (1), where axy= $1 / a_{x y}, a_{x y}>0$.

$$
A=\left|\begin{array}{ccc}
1 & a_{12} & a_{1 n} \\
a_{21} & 1 & a_{2 n} \\
a_{n 1} & a_{n 2} & 1
\end{array}\right| .
$$

As an indication of their degree of importance for the introduction of challenges faced by client organizations in hybrid cloud computing adoption, we further clarify the pairwise comparison of two enlisted challenging factors as $\mathrm{CH} 1$ and $\mathrm{CH} 2$. For example, if $\mathrm{CH} 1$ is five degrees greater than $\mathrm{CH} 2$, then, as shown in Tables 1 and 2, CH2 is noticed to be $1 / 5$ as compared to $\mathrm{CH} 1$. Through applying the same principle, we performed in Section 4 the pairwise

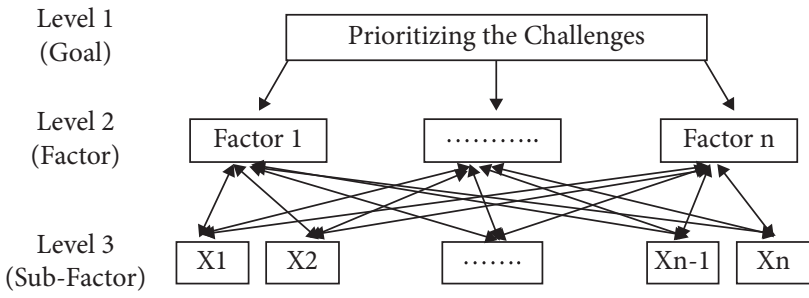

FIgURE 3: Hierarchical structure of problem.

comparison of matrixes for the overall identified challenging factors and their categorization.

In order to assess the rank of the identified challenges with the corresponding categories, the standard 9-point scale comparison was applied as depicted in Table 2.

The priority weight is determined based on the pairwise comparison matrixes as follows:

(1) $C$ refers to pairwise comparison for the recognized challenging factors.

(2) The normalized matrix [C] decomposes each element from every column via the sum from its concerned column.

(3) The priority weight [W] computes the average from each row from a normalized matrix [C].

3.3.4. Checking the Consistency for Pairwise Comparison Matrix. Shameem et al. [45] mentioned that pairwise comparison matrix in the AHP should be consistent and it could be calculated using the consistency index (CI) and consistency ratio (CR) as given in the following equations:

$$
\begin{aligned}
& \text { consistency index }(C I)=\frac{\lambda_{\max }-n}{(n-1)}, \\
& \text { consistency ratio }(C R)=\frac{C I}{R I} .
\end{aligned}
$$

By multiplication of given weight, $W$, and the summation of each column from a comparison matrix (see Section 4), the $\lambda$ max value is the prime eigenvalue which could be determined, where $n$ shows the total number for the identified challenges in the given numbers of pairwise comparison matrix. 
TABLE 1: Example of pairwise comparison.

\begin{tabular}{lcc}
\hline S. No & $\mathrm{CH} 1$ & $\mathrm{CH} 2$ \\
\hline $\mathrm{CH} 1$ & 1 & 5 \\
$\mathrm{CH} 2$ & $1 / 5$ & 1 \\
\hline
\end{tabular}

TABle 2: Description of intensity scale.

Description

Equally important

Moderately important

Strongly more important

Very strongly more important

Extremely more important

Intermediate values

RI shows the random consistency index (CI) in (3) and its value varies with respect to the size of matrix (see Table 3 ). The permissible CR value goes up to 0.10 , and the challenging priority vector is acceptable only if the CR value is less than 0.10 . Further, if the given CR value is not under the appropriate range, then there is a compulsory need to repeat the same process to enhance the degree of steadiness. In this paper, Section 4 presents the estimated value of CR for each comparison matrix.

\section{Results}

4.1. List of Challenging Factors Identified via SLR. Table 4 display a list of the challenges found via SLR1 that are regarded as the main roadblocks in the adoption of hybrid cloud. Our results show that "public cloud security concern" is the top of all challenges, i.e., 58\%. "This is because in hybrid cloud data security risk is high as some of the data is exposed to public cloud from the private cloud" [53]. According to Li et al. [54], "this challenge relates to keeping the amount of sensitive data that is exposed to the public machines." Balasubramanian and Murugaiyan [55] argue that "hybrid cloud model transfers selective data between public and private clouds." According to Wang et al. [56], "data externalization towards services deployed on the public cloud creates security problems coming from the data issued by public cloud services."

The results also show that the "effective management issue" $(28 \%)$ is the secondly cited challenge among all the identified challenges. This is because moving to hybrid cloud from public cloud environment needs an effective management in terms of managing the manageability issue of the cloud infrastructure in hybrid cloud environment [57]. According to Bhadauria et al. [58], "the risk of outsourced services going out of control is high in a hybrid cloud environment and key management becomes a difficult task in such situations."

"Integration complexity" in our findings was listed at the 3rd position among mostly cited challenges (23\%). Hybrid cloud technical integration is perceived to be much more difficult and a significant barrier to adoption. "Integration of one or more public and private clouds into a hybrid system can be more challenging than integrating on-premises systems" [59]. According to Javidi et al. [60], "a mechanism for integrating private and public clouds is one of the major issues that need to be addressed for realizing hybrid cloud computing infrastructure."

The "quality of service (QoS)" is another challenge in hybrid cloud adoption, which we have already discussed in the literature portion.

Jian and Sheng [61] determined that "different components of the hybrid infrastructure provide different QoS guarantees, efficient policies to integrate public and private cloud. However, to assure QoS target of the users remain a challenging job."

"Lack of trust has been reported as a challenge in the adoption of hybrid" [62]. Noor et al. [63] argue that "due to the fact that data owners and cloud storage providers are dispersed across distinct global sites, due to which it becomes difficult to establish trust between the client and public cloud provider in the hybrid cloud environment."

By following the structure established by Shameem et al. [45], the challenges found were further mapped into four categories, as shown in Figure 4.

4.2. Empirical Investigation. In order to empirically verify the identified results of SLR, we have performed an online questionnaire survey. We evaluated the data obtained, and this section contains the findings. The questionnaire survey contains demographic information and hybrid cloud adoption challenges identified through SLR. There were three sections in the questionnaire survey. Every section consisted of various open-ended questions for the purpose of extracting any other challenges beyond those which were identified via the SLR1. Seven-point Likert scale, i.e., "extremely agree (EA)," "moderately agree (MA)," "slightly agree (SA)," "not sure (NS)," "slightly disagree (SD)," "moderately disagree (MD)," "extremely disagree (ED)," was applied to conclude the views of the respondents about these identified challenges.

For data collection, a request was posted in different groups via LinkedIn, having more than fifty thousand members in total across the globe (see Table 5). Further, we also sent requests to different companies in Pakistan utilizing cloud services as shown in Table 6 to participate in the questionnaire survey. Our invitation request was responded to by 60 experts in total showing their willingness, through e-mail, to participate. Questionnaire was shared with these experts after receiving their consent for participation. A total of 33 participants took part in the survey. Among the filled questionnaires, 3 were rejected because they did not follow our predefined quality criteria. Accordingly, 30 responses were selected as the final sample and used for the analysis, showing a response rate of $50 \%$.

Table 7 shows the list of the challenges in the adoption of hybrid cloud that were identified/validated via empirical study. This table also depicts the various options through 7 point Likert scale for each of the aforementioned challenges and the graphical representation.

Table 7 shows that $\geq 80 \%$ of the respondents agreed that "public cloud security concern" (90\%), "lack of trust" (87\%), 
TABle 3: RI value with respect to matrix size.

\begin{tabular}{lllcccccccc}
\hline Size of matrix & 1 & 2 & 3 & 4 & 5 & 6 & 7 & 8 & 9 & 10 \\
\hline RI & 0 & 0 & 0.58 & 0.9 & 1.12 & 1.24 & 1.32 & 1.41 & 1.45 & 1.49 \\
\hline
\end{tabular}

TABLE 4: List of challenging factors identified through SLR1.

\begin{tabular}{|c|c|c|c|}
\hline $\begin{array}{l}\text { Public hybrid cloud computing } \\
\text { challenges }\end{array}$ & Freq & $\%$ & References \\
\hline Public cloud security concern & 69 & 58 & $\begin{array}{l}\text { [1],[2], [9], [13], [17], [18], [20], [23], [24], [27], [30], [33], [34], [35], [39], [41], [42], } \\
{[43],[44],[45],[47],[50],[53],[54],[55],[56],[58],[59],[61],[63],[65],[66],[67],} \\
{[68],[71],[72],[73],[76],[78],[79],[80],[81],[82],[83],[84],[85],[86],[87],[89],[91],} \\
{[92],[93],[95],[96],[97],[98],[99],[100],[101],[103],[104],[105],[106],[110],[112],} \\
{[114],[115],[116],[120]}\end{array}$ \\
\hline Effective management issue & 34 & 28 & $\begin{array}{l}{[1],[5],[8],[9],[15],[17],[18],[27],[28],[31],[37],[38],[39],[40],[44],[50],[56],[66],} \\
{[70],[74],[77],[78],[80],[84],[86],[88],[89],[102],[104],[105],[106],[107],[113],} \\
{[120]}\end{array}$ \\
\hline Integration complexity & 27 & 23 & $\begin{array}{c}{[5],[6],[17],[18],[32],[56],[58],[60],[65],[66],[69],[72],[73],[77],[78],[79],[80],} \\
{[86],[89],[92],[96],[100],[103],[105],[113],[116],[117]}\end{array}$ \\
\hline Achieving QoS & 15 & 13 & {$[4],[5],[11],[14],[23],[41],[57],[61],[65],[94],[106],[107],[108],[111],[119]$} \\
\hline Components partitioning & 15 & 13 & {$[3],[9],[12],[16],[20],[21],[52],[57],[60],[62],[68],[70],[109],[115],[118]$} \\
\hline Lack of trust & 14 & 12 & {$[7],[13],[19],[24],[30],[39],[54],[64],[71],[72],[85],[92],[114][116]$} \\
\hline SLA assurance & 14 & 12 & {$[16],[17],[25],[26],[30],[39],[41],[47],[48],[61],[66],[69],[80],[85]$} \\
\hline Task scheduling and execution & 13 & 11 & {$[4],[10],[22],[29],[36],[49],[51],[52],[70],[74],[75],[90],[93]$} \\
\hline Appropriate cloud offering & 5 & 4 & {$[38],[46],[86],[88],[102]$} \\
\hline Data searching & 1 & 0.8 & [114] \\
\hline Cost driven scheduling of services & 1 & 0.8 & {$[121]$} \\
\hline $\begin{array}{l}\text { Lack of sharing of resources across } \\
\text { multiple concerns }\end{array}$ & 1 & 0.8 & {$[122]$} \\
\hline
\end{tabular}

and "integration complexity" (83\%) are the highest challenges found in such a domain.

About $>60 \%$ respondents agreed about "QoS" (67\%), "SLA (service level agreement) assurance" (67\%), "task scheduling challenges" (63\%), "effective management" (63\%), and "component partitioning" (63\%). We suggest efficient policies implementation for these challenges. Although, there is little evidence in literature revealing "data searching" challenge, $60 \%$ of the respondents agreed that it is also a challenging factor or challenge in the embracing of hybrid cloud. 53\% of the respondents agreed about "appropriate cloud offering."

In addition, the participants of the survey were invited for the purpose of presenting their insights about other challenges which were not identified through the SLR conduction. However, we have not found any new challenge or recommendation given by the respondents of the survey.

\subsection{Crossway Comparison of Public Hybrid Cloud Computing} Challenges Identified through SLR1 and Questionnaire Survey. We validated public hybrid cloud computing challenges discovered via SLR1 with a survey questionnaire followup and then undertook comparative analysis of both outcome data sets. This analysis predictably leaned towards radiating extant similarities and disparities between SLR1 and survey outcomes (see Table 8 ). Table 8 presents a comparative analysis of both data sets using only positive values from the survey questionnaire. Lowest ranks were assigned to highest values. Whenever similar values occurred, we assigned an average rank and then approximated the value of the next rank. We further noted that rankings for cited challenges across both data sets were not the same. We used the Spearman's rank correlation test (formula) and identified a value of $R=0.54$, reflecting the frequency of a challenge's reference in the SLR correlation with its citation frequency among survey participants. This allows a relative appraisal for the similarity of importance for each SLR challenge compared to survey results.

$$
\begin{aligned}
\text { Spearman rank correlation }(R) & =1-\frac{6 \Sigma \mathrm{d} 2}{(n)^{3}-n} \\
& =1-\frac{6 \times 132.5}{(12)^{3}-12} \\
& =1-\frac{795}{1728-12} \\
& =1-\frac{795}{1716} \\
& =1-0.46 \\
& =0.54 .
\end{aligned}
$$

4.4. Application of AHP. The AHP method and its implementation are highlighted briefly in the following steps: 


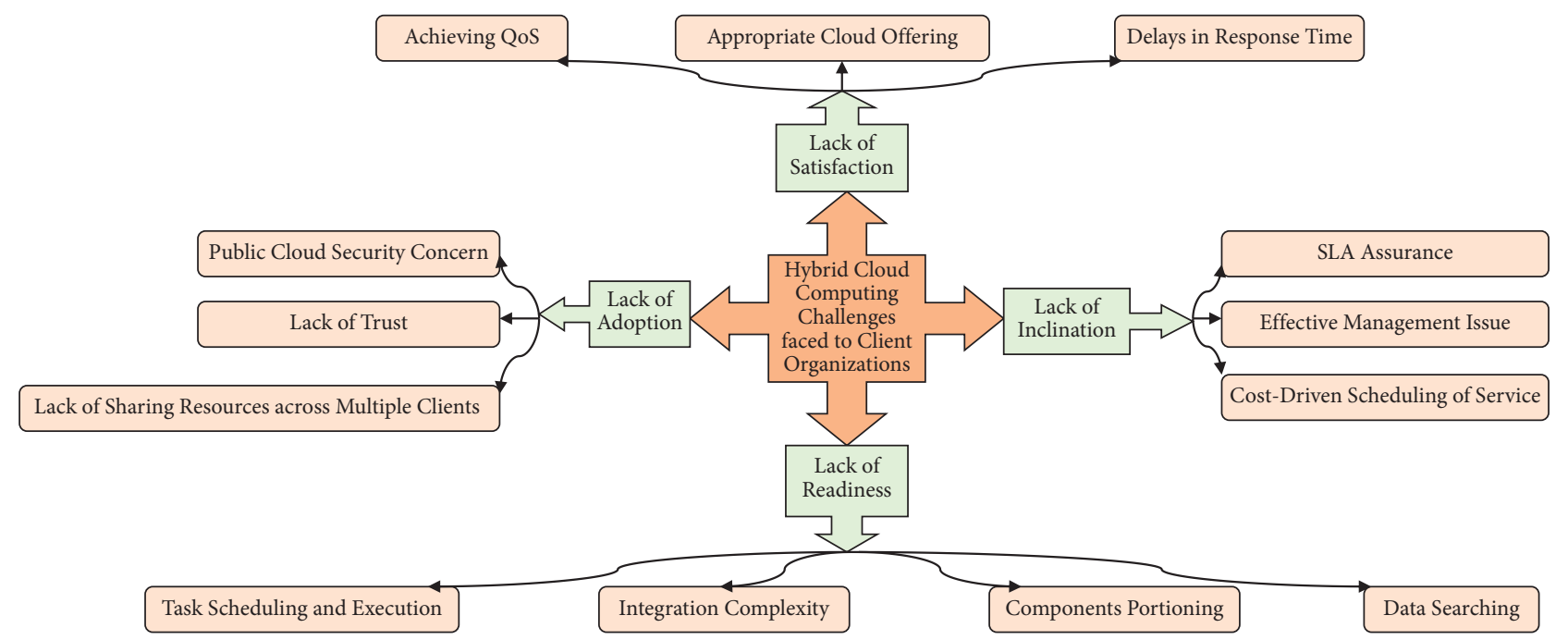

FIgURE 4: Categorization of hybrid cloud computing challenges.

TABLE 5: List of LinkedIn online cloud professionals.

\begin{tabular}{lccc}
\hline S. no. & Group name (available online at LinkedIn website) & Total members (at the time of request) & Date (request posted) \\
\hline 1 & Canada Cloud Network & 681 & 14 April 2015 \\
2 & Cloud Architect and Professionals Network & 6,354 & 14 April 2015 \\
3 & Conversations on Cloud Computing & 10,132 & 14 April 2015 \\
4 & Cloud Computing Best Practices & 7,950 & 14 April 2015 \\
5 & Hybrid Cloud User Group & 66 & 15 April 2015 \\
6 & SAP Cloud Computing (private, public, or hybrid) & 1,531 & 15 April 2015 \\
7 & TalkinCloud & 1,010 & 15 April 2015 \\
8 & Windows Azure \& Microsoft Cloud & 10,467 & 16 April 2015 \\
9 & Cloud Computing, Microsoft UK & 11,088 & 16 April 2015 \\
10 & IEEE Cloud Computing & 5,719 & 16 April 2015 \\
\hline
\end{tabular}

Step 1: decomposition of a complex-decision problem into a simple hierarchical structure.

Based on the corresponding categorization from Figure 4, the hierarchical structure is built and is shown in Figure 5. In the first level, the fundamental purpose of this analysis is presented; the corresponding challenging factors with the categories are offered at levels 2 to 3 of Figure 5, respectively.

Step 2: development of the pairwise comparison matrix and calculation of the prioritization $\mathrm{AL}$ weight.

For each group of these challenges with its corresponding categories, the generation of pairwise comparison matrix was performed on the basis of data collected via AHP. All details for such a comparison ("Lack of Inclination," "Lack of Readiness," "Lack of Adoption," and "Lack of Satisfaction") are given in Tables 9-12.

Likewise, in Table 13, the results for the stated pairwise comparison matrix categories are produced. We also used the normalized matrix comparison for the purpose of calculating the weights of these challenging factors.
The normalized values of each challenging factor are determined by dividing its value by the number of corresponding columns. The complete details of normalized matrix of each category ("Lack of Inclination," "Lack of Readiness," "Lack of Adoption," and "Lack of Satisfaction") are provided in Tables 9, 14,15 , and 16, respectively. Table 17 shows the findings of the normalized matrix comparison groups.

For each challenge, the weight value (W) is determined from the average number of the normalized values of the respective rows. For example, the weight values given in Table 18 show that $\mathrm{CH} 1$ is the most significant challenging factor in the "Lack of Inclination" category because it has high value as compared to the other challenging factors of the same category. However, $\mathrm{CH} 3$ is the least significant challenging factor because it has low weight value.

Step 3: checking of consistency.

We are able to measure the degree of consistency for the corresponding category, i.e., "Lack of Inclination" via the below parameters, discussed in Section 3: 
TABLE 6: List of some famous software development companies in Pakistan.

\begin{tabular}{|c|c|c|c|}
\hline $\begin{array}{l}\text { S. } \\
\text { no. }\end{array}$ & Software company name & Address & $\begin{array}{l}\text { Date of request } \\
\text { sent }\end{array}$ \\
\hline 1 & $\begin{array}{l}\text { Subhash Educational } \\
\text { Complex }\end{array}$ & Arbab Road, Peshawar, KPK & 14 April 2015 \\
\hline 2 & $\begin{array}{l}\text { Haq Institute of Computer } \\
\text { and IT }\end{array}$ & Main Ghazi Road, Lahore & 14 April 2015 \\
\hline 3 & PurePush & Abasyn Street 6, I/9, Islamabad, Pakistan & 14 April 2015 \\
\hline 4 & $\begin{array}{l}\text { DatumSquare IT Services Pvt. } \\
\text { Ltd. }\end{array}$ & Software Technology Park, I-9/3, Islamabad & 14 April 2015 \\
\hline 5 & Macrosoft Pakistan & Abu Bakar Block, New Garden Town, Lahore, Pakistan & 15 April 2015 \\
\hline 6 & Xavor Corporation & Masood Anwari Rd, Cavalry Extension, Cavalry Ground, Lahore & 15 April 2015 \\
\hline 7 & Xerox Soft (Pvt.) Ltd. & Deans Trade Center, Peshawar & 15 April 2015 \\
\hline 8 & Ovex technologies & $\begin{array}{c}\text { 1st Floor, KSL Complex, Software Technology Park, Plot No. 156, I-9/3 } \\
\text { Industrial Area, Islamabad }\end{array}$ & 16 April 2015 \\
\hline 9 & Techlogix & Empress Road, Lahore, Pakistan & 16 April 2015 \\
\hline
\end{tabular}

TABLE 7: List of challenges identified via empirical study.

\begin{tabular}{|c|c|c|c|c|c|c|c|c|c|c|c|}
\hline \multirow{3}{*}{ S. no. } & \multirow{3}{*}{ Identified challenging factors with categorization } & \multicolumn{10}{|c|}{ Expert perception $(n=30)$} \\
\hline & & \multicolumn{4}{|c|}{ Positive } & \multicolumn{3}{|c|}{ Negative } & \multicolumn{3}{|c|}{ Neutral } \\
\hline & & EA & MA & SA & $\%$ & $\mathrm{SD}$ & $\mathrm{MD}$ & ED & $\%$ & NS & $\%$ \\
\hline $\mathrm{C} 1$ & Category: lack of Inclination & 20 & 1 & 2 & 86 & 2 & 1 & 1 & 14 & 3 & 10 \\
\hline $\mathrm{CH} 1$ & Effective management issue & 19 & 6 & 4 & 97 & 0 & 0 & 0 & 0 & 1 & 3 \\
\hline $\mathrm{CH} 2$ & SLA assurance & 20 & 6 & 2 & 93 & 0 & 0 & 0 & 0 & 2 & 7 \\
\hline $\mathrm{CH} 3$ & Cost-driven scheduling of service & 10 & 8 & 3 & 70 & 3 & 2 & 1 & 23 & 3 & 10 \\
\hline $\mathrm{C} 2$ & Category: lack of Readiness & 21 & 2 & 3 & 89 & 0 & 1 & 1 & 4 & 2 & 7 \\
\hline $\mathrm{CH} 4$ & Task scheduling and execution & 19 & 3 & 6 & 93 & 0 & 0 & 0 & 0 & 2 & 7 \\
\hline $\mathrm{CH} 5$ & Data searching & 18 & 7 & 3 & 93 & 0 & 1 & 0 & 3 & 1 & 3 \\
\hline $\mathrm{CH} 6$ & Integration complexity & 20 & 3 & 3 & 86 & 2 & 0 & 0 & 7 & 2 & 7 \\
\hline $\mathrm{CH} 7$ & Components partitioning & 19 & 2 & 4 & 83 & 1 & 0 & 0 & 3 & 4 & 14 \\
\hline $\mathrm{C} 3$ & Category: lack of Adoption & 22 & 2 & 2 & 88 & 1 & 1 & 1 & 9 & 1 & 3 \\
\hline $\mathrm{CH} 8$ & Public cloud security concern & 23 & 2 & 4 & 97 & 0 & 1 & 0 & 2 & 0 & 0 \\
\hline $\mathrm{CH} 9$ & Lack of trust & 24 & 3 & 1 & 93 & 0 & 0 & 0 & 0 & 2 & 7 \\
\hline $\mathrm{CH} 10$ & Lack of sharing resources across multiple clients & 9 & 7 & 6 & 73 & 2 & 1 & 3 & 27 & 2 & 7 \\
\hline $\mathrm{C} 4$ & Category: lack of Satisfaction & 20 & 3 & 2 & 83 & 2 & 0 & 0 & 7 & 3 & 10 \\
\hline $\mathrm{CH} 11$ & Achieving QoS & 20 & 6 & 3 & 97 & 0 & 0 & 0 & 0 & 1 & 3 \\
\hline $\mathrm{CH} 12$ & Appropriate cloud offering & 16 & 11 & 0 & 90 & 0 & 0 & 0 & 0 & 3 & 10 \\
\hline $\mathrm{CH} 13$ & Delays in response time & 10 & 6 & 4 & 66 & 2 & 1 & 3 & 20 & 4 & 14 \\
\hline
\end{tabular}

TABLE 8: Crossway comparison of public hybrid cloud computing challenges identified through SLR1 and questionnaire survey.

\begin{tabular}{|c|c|c|c|c|c|c|c|}
\hline \multirow[t]{2}{*}{ S. no. } & \multirow[t]{2}{*}{ Public hybrid cloud computing challenges } & \multicolumn{4}{|c|}{$\begin{array}{c}\text { Positive } \\
\text { agreement } \\
(\%) \text { in the } \\
\text { questionnaire } \\
\text { survey } \\
(N=33)\end{array}$} & \multirow[t]{2}{*}{$d$} & \multirow[t]{2}{*}{$d^{2}$} \\
\hline & & $\%$ & Rank & $\%$ & Rank & & \\
\hline 1 & Public cloud security concern & 58 & 1 & 97 & 1.5 & -0.5 & 0.25 \\
\hline 2 & Effective management issue & 28 & 2 & 97 & 1.5 & 0.5 & 0.25 \\
\hline 3 & Integration complexity & 23 & 3 & 86 & 9 & -6 & 36 \\
\hline 4 & Achieving QoS & 13 & 4.5 & 97 & 1.5 & 2.5 & 6.25 \\
\hline 5 & Components partitioning & 13 & 4.5 & 83 & 10 & -5.5 & 30.25 \\
\hline 6 & Lack of trust & 12 & 6.5 & 93 & 4.5 & 2 & 4 \\
\hline 7 & SLA assurance & 12 & 6.5 & 93 & 4.5 & 2 & 4 \\
\hline 8 & Task scheduling and execution & 11 & 8 & 93 & 4.5 & 3.5 & 12.25 \\
\hline 9 & Appropriate cloud offering & 4 & 9 & 90 & 8 & 1 & 1 \\
\hline 10 & Data searching & 0.8 & 10.5 & 93 & 4.5 & 6 & 36 \\
\hline 11 & Cost driven scheduling of services & 0.8 & 10.5 & 70 & 12 & -1.5 & 2.25 \\
\hline 12 & $\begin{array}{l}\text { Lack of sharing of resources across multiple concerns } \\
\qquad n=12\end{array}$ & 0.8 & 10.5 & 73 & 11 & -0.5 & $\begin{array}{c}0.25 \\
\Sigma d^{2}=132.5\end{array}$ \\
\hline
\end{tabular}




$$
\lambda \max =\sum\left(\left[\sum C j\right] \times\{W\}\right)
$$

where $\Sigma \mathrm{Cj}$ is the summation of columns from matrix [C], which is depicted in Table 10, and $W$ is the weight vector (see Table 15).

$$
\begin{aligned}
\lambda_{\max } & =(2.00 \times 0.46) \pm(3.58 \times 0.31) \pm(7.25 \times 0.16) \pm(16.00 \times 0.06), \\
\lambda_{\max } & =0.92+1.1098 \pm 1.16+0.96, \\
\lambda_{\max } & =4.1498, \\
\text { Consistency Index }(\mathrm{CI}) & =\frac{\lambda_{\max }-n}{(n-1)}=\frac{4.1498-4}{(4-1)}=\frac{0.1498}{(3)}, \\
\text { Random Index }(\mathrm{RI}) & =0.9, \\
\text { Consistency Ratio }(\mathrm{CR}) & =\frac{\mathrm{CI}}{\mathrm{RI}}=\frac{0.049}{0.9} \\
& =0.058<0.1 \text { (consitency is OK). }
\end{aligned}
$$

The result given indicates that the CR value is lower than 0.1 , which is the appropriate CR value. For such challenging factors in all the other corresponding categories, the same accuracy method is used, and the estimation of the CR value is given in Tables 9, 10, 14, 16, and 18 .

Step 4: provision of local and global ranking for challenging factors with their categories.

For each of the stated challenges, the local weight (LW) and global weight (GW) are presented in Table 19, where the local weight reflects the importance of the related challenging factor in its own specified category, while the global weight shows the specified priority for a factor across all the 13 challenging factors identified.

The LW was determined by performing a pairwise comparison for each of the challenging factors and the category (see step 3). For example, Table 19 shows that the LW of CH1 (0.63) is found to be the highest weight in the "Lack of Inclination" category; therefore, $\mathrm{CH} 1$ is also the uppermost ranked, prioritized challenging factor in the "Lack of Inclination" category.

Likewise, by multiplication of their LW and that of their respective groups, we calculated the GW of the reported challenging factors. For example, GW of challenging factor $\mathrm{CH} 1=0.10 \times 0.63=0.063$, where 0.10 is the weight of its category (Lack of Inclination) and 0.63 is its LW. The same process is repeated for the remaining challenging factors, and their GW is calculated, respectively, as presented in Table 19.

Step 5: finalized prioritization of these challenging factors.

The finalized priority of these challenge factors is, typically, based on the GW for each of the challenge factors, and the same is presented in Table 19. On top priority, challenging factors that have higher GW in all categories are taken into account.

In Table 19, CH8 (public cloud security concern) and CH11 (achieving QoS) are considered as the uppermost ranking challenging factors due to their GW value (0.201), which is the highest value as compared to the other factors.

We further noted that $\mathrm{CH} 12$ (appropriate cloud offering) is found to be the secondly highest common challenging factor that could adversely affect the receipt of hybrid cloud computing activities from client organizations' perspective.

4.5. Practices for Critical Challenges Identified through SLR 2 and Empirical Study. In this section, a list of practices is presented for each CC (critical challenge) identified through SLR1. We considered that 8 challenges are critical because they have high frequencies both in SLR1 and empirical study findings. We have designed 46 practices in total for the 8 CCs. These practices were identified via SLR2 and questionnaires surveys with 30 experts.

We have presented under each challenge its relevant practices for addressing the particular challenge. In Table 20 CCs represent critical challenges and CCPs represent practices for addressing these challenges.

\section{Discussion}

5.1. RQ1 (Challenges Faced by Client Organizations in the Adoption of Hybrid Cloud Computing). We have closely analyzed 120 articles and extracted a total of 13 challenging factors that could adversely affect the world of hybrid cloud computing. Section 4 addresses and summarizes these factors in detail. Following the defined principles for the system introduced by Shameem et al. [45], the reported challenging factors were further classified and presented as a theoretical mode. 


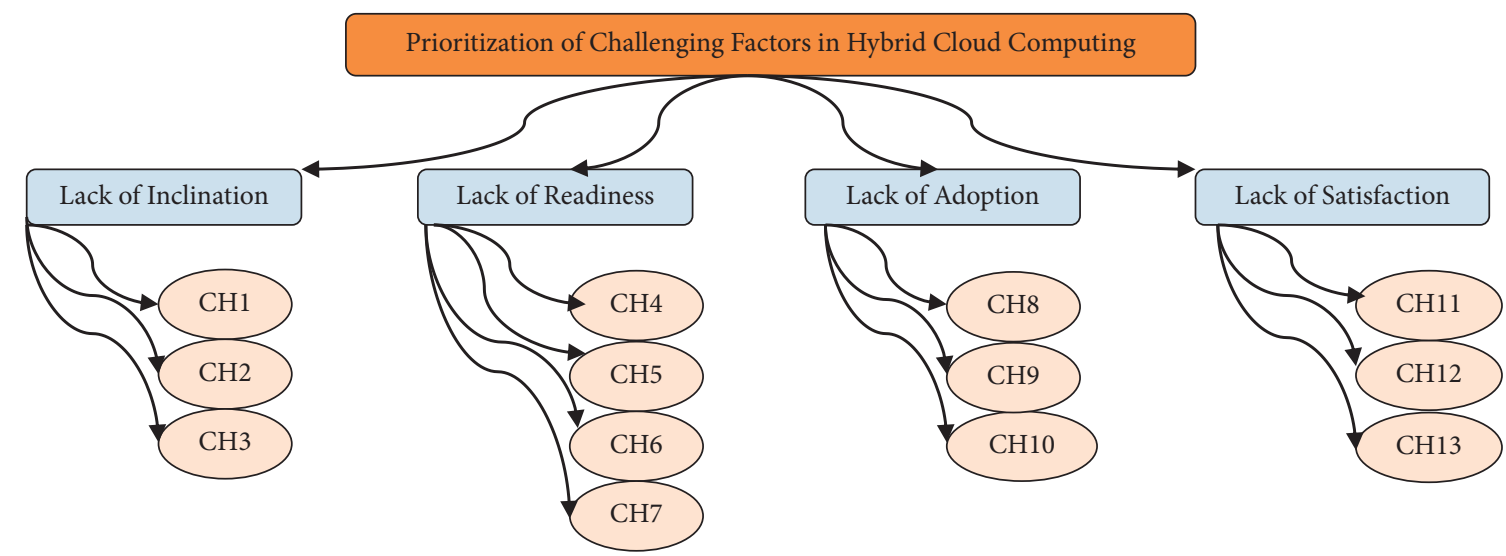

Figure 5: Hierarchal structure of challenging factors.

TABLE 9: Normalized matrix of "Lack of Adoption" category.

\begin{tabular}{lcccc}
\hline S. no. & CH8 & CH9 & CH10 & Weight $($ W) \\
\hline CH8 & 0.61 & 0.63 & 0.36 & 0.53 \\
CH9 & 0.50 & 0.32 & 0.57 & 0.40 \\
CH10 & 0.09 & 0.05 & 0.07 & 0.07 \\
\hline
\end{tabular}

$\lambda_{\max }=3.067, C I=0.034, R I=0.58, C R=0.06<0.1$.

TABLE 10: Pairwise matrix comparison for the challenging factors of "Lack of Readiness" category.

\begin{tabular}{lcccc}
\hline S. no. & CH4 & CH5 & CH6 & CH7 \\
\hline CH4 & 1 & 2 & 3 & 6 \\
CH5 & $1 / 2$ & 1 & 3 & 5 \\
CH6 & $1 / 3$ & $1 / 3$ & 1 & 4 \\
CH7 & $1 / 6$ & $1 / 5$ & $1 / 4$ & 1 \\
Sum & 2.00 & 3.58 & 7.25 & 16.00 \\
\hline
\end{tabular}

A questionnaire analysis with 30 experts from hybrid cloud computing professionals as well as academic researchers, conducted empirically, validates the results of the SLR1.

5.2. RQ2 (Prioritization Process for Hybrid Cloud Challenging Factors). For such a process of prioritization, the AHP approach implemented was selected because it plays a key role in solving such a type of problems due to its classical multiple-criteria decision-making, MCDM, nature, introduced by Saaty [44]. Typically, the approach to ranking and prioritizing the given variables is accurate and precise.

In this paper, we use AHP to prioritize the factors found in the adoption of hybrid cloud computing faced by client organizations. Table 19 indicates that $\mathrm{CH} 8$ (public cloud security concern) and CH11 (achieving QoS) have been considered as the highest-ranking challenging factors, faced by client organizations in adoption of hybrid cloud computing because their GW (0.201) is higher as compared to all the other reported challenging factors. by Client Organizations in the Adoption of Hybrid Cloud
Computing). For such a purpose, we performed a second systematic literature review, SLR2, and extracted a total of 46 practices from a sample of 90 papers. These practices are discussed and summarized in detail in Section 4 (Tables 20-27). By conducting a questionnaire survey with 30 experts from hybrid cloud computing professionals and academic scholars, the results of SLR2 were empirically checked.

5.4. RQ4 (Taxonomy for the Challenging Factors). Figure 6 shows the taxonomy for such challenging factors, where it is generated via measuring of both the LW value and the GW value of each challenging factor with its corresponding category based on AHP prioritization. This figure shows that "Lack of Adoption" (0.38) and "Lack of Satisfaction" (0.38) are considered as the most prioritized categories by the survey experts. The weights of these categories are maximum as compared with the other categories.

Further, we have noted that $\mathrm{CH} 8$ (public cloud security concern) and CH11 (achieving QoS) have been considered as the highest-ranking challenging factors, which are also listed in these categories, because of their GW value (i.e., 0.201) which is found to be higher than those of all other challenging factors mentioned.

\section{Summarizing the Research Questions}

This research aims to deliver a taxonomy, on the basis of AHP technique, for the challenging factors or challenges faced by client organizations in hybrid cloud computing. The conclusions of this article provide help to effectively navigate the practices of hybrid cloud computing. In Table 28, the description of the research questions is given. 
TABLE 11: Pairwise matrix comparison for the challenging factors of "Lack of Adoption" category.

\begin{tabular}{lccc}
\hline S. no. & CH8 & CH9 & CH10 \\
\hline CH8 & 1 & 2 & 5 \\
CH9 & $1 / 2$ & 1 & 8 \\
CH10 & $1 / 5$ & $1 / 8$ & 1 \\
Sum & 1.64 & 3.16 & 14.00 \\
\hline
\end{tabular}

TABle 12: Pairwise matrix comparison for the challenging factors of "Lack of Satisfaction" category.

\begin{tabular}{lccc}
\hline S. no. & CH11 & CH12 & \\
\hline CH11 & 1 & 3 & CH13 \\
CH12 & $1 / 3$ & 1 & 6 \\
CH13 & $1 / 8$ & $1 / 6$ & 1 \\
Sum & 1.45 & 4.17 & 15.00 \\
\hline
\end{tabular}

TABle 13: Pairwise matrix comparison between categories of challenging factors.

\begin{tabular}{lcccc}
\hline S. no. & Lack of Inclination & Lack of Readiness & Lack of Adoption & Lack of Satisfaction \\
\hline Lack of Inclination & 1 & $1 / 2$ & $1 / 3$ & $1 / 3$ \\
Lack of Readiness & 2 & 1 & $1 / 4$ & $1 / 4$ \\
Lack of Adoption & $1 / 3$ & $1 / 3$ & 1 & 4 \\
Lack of Satisfaction & $1 / 6$ & $1 / 5$ & $1 / 4$ & 1 \\
Sum & 2.00 & 3.58 & 7.25 & 16.00 \\
\hline
\end{tabular}

TABLE 14: Normalized matrix of "Lack of Inclination" category.

\begin{tabular}{lllll}
\hline S. no. & CH1 & CH2 & CH3 & Weight (W) \\
\hline CH1 & 0.68 & 0.72 & 0.50 & 0.63 \\
CH2 & 0.22 & 0.24 & 0.43 & 0.30 \\
CH3 & 0.10 & 0.04 & 0.07 & 0.07 \\
\hline
\end{tabular}

$\lambda_{\max }=3.099, C I=0.049, R I=0.58, C R=0.09<0.1$.

TABLE 15: Normalized matrix of "Lack of Inclination" category.

\begin{tabular}{llllll}
\hline S. no. & CH4 & CH5 & CH6 & CH7 & 0.38 \\
CH4 & 0.50 & 0.56 & 0.41 & 0.31 & 0.46 \\
CH5 & 0.25 & 0.28 & 0.41 & 0.25 & 0.31 \\
CH6 & 0.17 & 0.09 & 0.14 & 0.06 & 0.16 \\
CH7 & 0.09 & 0.07 & 0.03 & 0.06 \\
\hline
\end{tabular}

TABLE 16: Normalized matrix of "Lack of Satisfaction" category.

\begin{tabular}{lllll}
\hline S. no. & CH8 & CH9 & CH10 & Weight (W) \\
\hline CH8 & 0.61 & 0.63 & 0.36 & 0.53 \\
CH9 & 0.30 & 0.32 & 0.57 & 0.40 \\
CH10 & 0.09 & 0.05 & 0.07 & 0.07 \\
\hline
\end{tabular}

$\lambda_{\max }=3.067, C I=0.034, R I=0.58, C R=0.06<0.1$.

TABLE 17: Normalized matrix for the categories of challenging factors.

\begin{tabular}{lccccc}
\hline S. no. & Lack of Inclination & Lack of Readiness & Lack of Adoption & Lack of Satisfaction & Weight (W) \\
\hline Lack of Inclination & 0.11 & 0.05 & 0.13 & 0.13 & 0.10 \\
Lack of Readiness & 0.22 & 0.11 & 0.10 & 0.10 & 0.39 \\
Lack of Adoption & 0.33 & 0.42 & 0.39 & 0.39 \\
Lack of Satisfaction & 0.33 & 0.42 & 0.39 & 0.38 \\
\hline
\end{tabular}

$\lambda_{\max }=4.199, C I=0.040, R I=0.9, C R=0.04<0.1$. 
TABLE 18: Pairwise matrix comparison for the extracted challenging factors of "Lack of Inclination" category.

\begin{tabular}{lccc}
\hline S. no. & $\mathrm{CH} 1$ & $\mathrm{CH} 2$ & $\mathrm{CH} 3$ \\
\hline $\mathrm{CH} 1$ & 1 & 3 & 7 \\
$\mathrm{CH} 2$ & $1 / 3$ & 1 & 6 \\
$\mathrm{CH} 3$ & $1 / 7$ & $1 / 6$ & 1 \\
Sum & 1.47 & 4.17 & 14.00 \\
\hline
\end{tabular}

TABle 19: Summarized list for the challenging factors being ranked.

\begin{tabular}{|c|c|c|c|c|c|c|}
\hline Categories & Categories weight & Challenging factors & Local weight & Local ranking & Global weight & Priority \\
\hline \multirow{3}{*}{ Lack of Inclination } & \multirow{3}{*}{0.10} & $\mathrm{CH} 1$ & 0.63 & 1 & 0.063 & 5 \\
\hline & & $\mathrm{CH} 2$ & 0.30 & 2 & 0.030 & 8 \\
\hline & & $\mathrm{CH} 3$ & 0.07 & 3 & 0.070 & 4 \\
\hline \multirow{4}{*}{ Lack of Readiness } & \multirow{4}{*}{0.13} & $\mathrm{CH} 4$ & 0.46 & 1 & 0.060 & 6 \\
\hline & & $\mathrm{CH} 5$ & 0.31 & 2 & 0.040 & 7 \\
\hline & & $\mathrm{CH} 6$ & 0.16 & 3 & 0.020 & 11 \\
\hline & & $\mathrm{CH} 7$ & 0.06 & 4 & 0.078 & 3 \\
\hline \multirow{3}{*}{ Lack of Adoption } & \multirow{3}{*}{0.38} & $\mathrm{CH} 8$ & 0.53 & 1 & 0.201 & 1 \\
\hline & & $\mathrm{CH} 9$ & 0.40 & 2 & 0.152 & 2 \\
\hline & & $\mathrm{CH} 10$ & 0.07 & 3 & 0.026 & 10 \\
\hline \multirow{3}{*}{ Lack of Satisfaction } & \multirow{3}{*}{0.38} & $\mathrm{CH} 11$ & 0.53 & 1 & 0.201 & 1 \\
\hline & & $\mathrm{CH} 12$ & 0.40 & 2 & 0.152 & 2 \\
\hline & & $\mathrm{CH} 13$ & 0.07 & 3 & 0.026 & 9 \\
\hline
\end{tabular}

TABLe 20: Practices for addressing critical challenge "SLA assurance."

CC\#1. SLA assurance

SLR2

Questionnaire survey

Frequency of SLR2 $(N=90)$

Positive \%

S. no.

Practices for addressing SLA assurance

2

ECP\#
Ense the maximum availability of services, provided by cloud providers,
duration of the contract period are explicitly defined in the SLA.

CCP\#1.2 Define explicitly in the SLA terms and conditions regarding the security of the clients' data.

CCP\#1.3 Keep the clients aware of where the processes are running or where the data is stored to ensure the security of the clients' data.

To mitigate the risk of a cloud provider failure, specify reversion strategies in the

CCP\#1.4 $\begin{aligned} & \text { SLA. This is because they put cloud customers in a much stronger position when } \\ & \text { renegotiating a cloud service contract because cloud customers know that they could }\end{aligned}$ readily switch from the provider if needed.

CCP\#1.5 Perform third-party auditing regularly to monitor the cloud service provider's compliance to agreed terms.

CCP\#1.6 Ensure in service level agreements what the contingency plans are in case of the breakdown of the system.

CCP\#1.7 On-premises gateway should be used in hybrid cloud for controlling the applications and data that flow from each part to the other.

Categorize the data into two parts, i.e., sensitive and nonsensitive. Place the sensitive

CCP\#1.8 data in the on-premises side (private cloud) whereas nonsensitive data should be kept in public cloud.

$\begin{array}{ll}2 & 98 \\ 8 & 81 \\ 2 & 96 \\ 2 & 94 \\ 4 & 92 \\ 6 & 97 \\ 6 & 94 \\ 16 & 100\end{array}$

\section{Research Limitations}

We adopted the SLR for the identification of challenging factors; consequently, there is a chance that we might have missed out some relevant paper(s) for inclusion in the final selection for extraction of the relevant challenging factors. However, this is not a systematic omission as other researchers also conducted the same process for the identification and categorization of factors/variables in other different domains [47-49, 64].

Due to the shortage of time and resource, the sample size for the study we have chosen was 30 (i.e., $n=30$ ), and so in this manner we are unable to claim generalized results. Nonetheless, other scholars from software engineering domain performed similar studies with the same sample size $[65,66]$. 
TABLe 21: Practices for addressing critical challenge "effective management issue."

\begin{tabular}{|c|c|c|c|}
\hline & CC\#2. Effective management issue & SLR2 & $\begin{array}{l}\text { Questionnaire } \\
\text { survey }\end{array}$ \\
\hline S. no. & Practices for addressing effective management issue & $\begin{array}{l}\text { Frequency of SLR2 } \\
\qquad(N=90)\end{array}$ & Positive \% \\
\hline ССР\#2.1 & $\begin{array}{l}\text { Use management tools developed by several working groups like open grid forum, } \\
\text { open cloud computing interface (OCCI), and storage network industry association } \\
\text { (SNIA) to monitor the performance of both internal and external resources. }\end{array}$ & 2 & 87 \\
\hline CCP\#2.2 & $\begin{array}{c}\text { Create a plan for release and deployment management that is appropriate for using } \\
\text { and living in cloud settings }\end{array}$ & 1 & 91 \\
\hline $\mathrm{CCP} \# 2.3$ & $\begin{array}{c}\text { Place a strong service portfolio management for continual service improvement } \\
\text { process. }\end{array}$ & 1 & 87 \\
\hline ССР\#2.4 & $\begin{array}{c}\text { Set a plan for capacity management (business capacity management, service capacity } \\
\text { management, and component capacity management) to improve performance } \\
\text { relating to both services and resources. }\end{array}$ & 1 & 88 \\
\hline СCР\#2.5 & $\begin{array}{l}\text { Implement tools like Ansible, CFEngine, Chep, Elastra and RightScale Puppet, and } \\
\text { Salt for addressing configuration and change management to control the lifecycle of } \\
\text { all changes which will assist in enabling beneficial changes to be made with minimum } \\
\text { disruption to IT services. }\end{array}$ & 1 & 87 \\
\hline СCР\#2.6 & $\begin{array}{l}\text { Keep backups of applications and data on on-premises servers and storage devices to } \\
\text { avoid data loss and time delays in case of failures in the cloud platform. }\end{array}$ & 4 & 97 \\
\hline $\mathrm{CCP} \# 2.7$ & $\begin{array}{l}\text { Consider a cost-effective model to decide which task is economical on the cloud or } \\
\text { internal resources. }\end{array}$ & 3 & 84 \\
\hline ССР\#2.8 & $\begin{array}{l}\text { Perform efficient planning and implementation strategies before moving to the } \\
\text { hybrid cloud. }\end{array}$ & 2 & 97 \\
\hline
\end{tabular}

TABLE 22: Practices for addressing critical challenge "integration complexity."

\begin{tabular}{|c|c|c|c|}
\hline & CC\#3. Integration complexity & SLR2 & $\begin{array}{l}\text { Questionnaire } \\
\text { survey }\end{array}$ \\
\hline S. no. & Practices for addressing integration complexity & $\begin{array}{l}\text { Frequency of practices via } \\
\text { SLR2 }(N=90)\end{array}$ & Positive \% \\
\hline ССР\#3.1 & $\begin{array}{l}\text { Use the available infrastructures such as Eucalyptus, OpenNebula, and open } \\
\text { source software frameworks, in order to assist integration (front end } \\
\text { integration, data integration, and process integration) in hybrid cloud. }\end{array}$ & 3 & 87 \\
\hline СCР\#3.2 & $\begin{array}{l}\text { Use standard API (application programming interface) to integrate } \\
\text { applications and data between the private clouds and the public clouds. }\end{array}$ & 5 & 97 \\
\hline CCР\#3.3 & $\begin{array}{l}\text { Adopt technologies such as information integration, enterprise application } \\
\text { integration, and enterprise service bus for effective integration. }\end{array}$ & 3 & 90 \\
\hline ССР\#3.4 & $\begin{array}{l}\text { Establish integration mechanism to be controlled dynamically in response to } \\
\text { changes in business requirements with the passage of time. }\end{array}$ & 1 & 79 \\
\hline CCP\#3.5 & $\begin{array}{l}\text { Select form number of vendors offering solutions for data integration including } \\
\text { companies such as Dell Boomi, IBM, Informatica, Pervasive Software, Liaison } \\
\text { Technologies, and Talend. }\end{array}$ & 1 & 84 \\
\hline
\end{tabular}

As the construct validity refers to testing the accuracy of the appraisal on the basis of provided variables, the available literature, discussed here, describes the challenging factors and their practices that are tested empirically by using the online survey strategy. The findings from such empirical study show that the challenges and practices given are linked to the findings of SLR1 and SLR2, which explain the accuracy of the appraisal scale we had chosen.

Similarly, the internal validity is the assessment of a particular study's findings and interpretation. In this respect, we had conducted a pilot study with the members of SERGUOM that offers an appropriate degree of internal validity.
External validity is the generalizations of a research article's findings. In this study, the majority of the survey respondents belonged to Pakistan which was a challenge to external validity by generalizing the findings in comparison to other countries. There are, however, still some participants from different countries and, above all, we have not found any substantial variations between the findings from SLR and industrial survey; thus, we are confident that the results can be generalized by the data sample.

In addition, majority of the respondents were experienced practitioners in the same field, so we concluded that they have given their adequate input on the basis of their understanding of the difficult factors and their practices. 
TABLe 23: Practices for addressing critical challenge "achieving QoS."

\begin{tabular}{|c|c|c|c|}
\hline \multicolumn{2}{|r|}{ CC\#4. Achieving QoS } & \multirow{2}{*}{$\begin{array}{l}\text { SLR2 } \\
\text { Frequency of practices via } \\
\text { SLR }(N=90)\end{array}$} & \multirow{2}{*}{$\begin{array}{l}\text { Questionnaire } \\
\text { survey } \\
\text { Positive \% }\end{array}$} \\
\hline S. no. & Practices for addressing QoS & & \\
\hline ССР\#4.1 & $\begin{array}{l}\text { Select a cloud provider that can offer improved services in the following QoS } \\
\text { parameters/attributes: price, offered load, job deadline constraint, energy } \\
\text { consumption of the integrated infrastructure, security, etc. }\end{array}$ & 1 & 97 \\
\hline ССР\#4.2 & $\begin{array}{l}\text { Ensure that access to the internal infrastructure is only possible through secure } \\
\text { communications. }\end{array}$ & 3 & 94 \\
\hline ССР\#4.3 & $\begin{array}{l}\text { Follow secure communication protocols (such as Transport Layer Security } \\
\text { (TLS) and its predecessor, Secure Sockets Layer (SSL)) when communicating } \\
\text { with endpoint applications and databases. }\end{array}$ & 1 & 97 \\
\hline ССР\#4.4 & $\begin{array}{c}\text { Select a public cloud provider which can offer the capacity needed by internal } \\
\text { cloud and execute dynamically. }\end{array}$ & 1 & 93 \\
\hline ССР\#4.5 & $\begin{array}{l}\text { Select a cloud provider that can ensure high degree of availability of services at } \\
\text { all times. }\end{array}$ & 2 & 97 \\
\hline
\end{tabular}

TABLE 24: Practices for addressing critical challenge "component partitioning."

\section{CC\#5. Component partitioning}

S. no.

Practices for addressing component partitioning

\section{SLR2}

Frequency of practices via $\operatorname{SLR}(N=90)$
Questionnaire survey

Positive \%

In order to distribute an application over a hybrid cloud, the following parameters should be kept in mind:

(i) Data disclosure risk.

1

(ii) Resource allocation cost.

(iii) Private cloud load.

In order to migrate some of the applications components from private cloud to public cloud in the context of hybrid cloud environment, implement migration

CCP\#5.2 progress management functions like pacer which is capable of accurately predicting the migration time and coordinating the migrations of multiple application component.

Divide the workload to be executed across local and public clouds so that the

CCP\#5.3 workloads can move among resource pools, which will result in a well-designed cloud environment.

CCP\#5.4 Replicate some part of the data to the public side so as to enable the distribution of the computation.

CCP\#5.5 Consider a sensitivity-aware data partitioning mechanism like Sedic that guarantees that no sensitive data is exposed to public cloud.

$2 \quad 87$

$1 \quad 94$

$1-88$

1

TABle 25: Practices for addressing critical challenge "lack of trust."

\section{CC\#6. Lack of trust}

S. no.

Practices for addressing lack of trust.

\section{SLR2}

Frequency of practices via SLR2 $(N=90)$
Questionnaire survey

Positive \%

CCP\#6.1 Establish trustworthy relationships with cloud service providers through service level agreement (SLA).

3

1

implement, deploy, and manage security.

CCP\#6.2 Ensure the provision of security at different levels, i.e., how cloud providers Keep in mind that clients are still ultimately responsible for compliance and protection of their critical data, even if that workload had moved to the cloud. Use services of a broker in order to negotiate trust relationships with cloud providers.

CCP\#6.4 Ensure what sort of certifications the cloud providers have in place which can ensure service quality of the cloud provider.

$\begin{array}{ll}3 & 97 \\ 1 & 97 \\ 1 & 94 \\ 4 & 90 \\ 3 & 84\end{array}$


TABLE 26: Practices for addressing critical challenge "public cloud security concern."

CC\#7. Public cloud security concern

S. no.
Practices for addressing cloud security concern
SLR2

Frequency of practices via SLR2 $(N=90)$
Questionnaire survey

Positive \%

CCP\#7.1 Cloud security should be controlled by the client organization and not by the cloud vendor.

Provide effective authentication for users based on access control rights. Only the users who are authorized to access the private cloud can be directed to the

CCP\#7.2 private cloud; they can also access the public cloud. The rest of users who are not authorized to access the private cloud can be directed to the public cloud; they can access the public cloud only.

CCP\#7.3 Client organizations should use a third-party tool to enhance the security. Client organizations should utilize their private (own) resources as much as

CCP\#7.4 possible and outsource minimum tasks to the public cloud to maximize security.

Client organizations should carefully manage virtual images in a hybrid

CCP\#7.5 lient organizations should carefully manage virtual images in a hybri
environment using tools like firewall, IDS/IPS, and log inspection.

CCP\#7.6 Data should be encrypted by the client before outsourcing to cloud computing.

CCP\#7.7 The on-premises gateway should be used in a hybrid cloud for controlling the applications and data that flow from each part to the other.

Categorize the data into two parts, i.e., sensitive and nonsensitive. Place the

CCP\#7.8 sensitive data in the on-premises side (private cloud) whereas nonsensitive data should be kept in the public cloud.
2

97

8

2

2

94

493

697

64

16

100

TABLE 27: Practices for addressing critical challenge "task scheduling and execution."

\begin{tabular}{|c|c|c|c|}
\hline S. no. & $\begin{array}{l}\text { CC\# 8. Task scheduling and execution } \\
\text { Practices for addressing task scheduling and execution }\end{array}$ & $\begin{array}{l}\text { Frequency of practices via } \\
\text { SLR }(N=90)\end{array}$ & $\begin{array}{l}\text { Questionnaire } \\
\text { survey } \\
\text { Positive \% }\end{array}$ \\
\hline ССР\#8.1 & $\begin{array}{c}\text { Use of an efficient scheduling mechanism/ algorithm to enable efficient } \\
\text { utilization of the on-premise resources and to minimize the task outsourcing } \\
\text { cost, while meeting the task completion time requirements as well. These } \\
\text { scheduling algorithms include Hybrid Cloud Optimized Cost (HCOC), } \\
\text { Deadline-Markov Decision Process (MDP), Heterogeneous Earliest Finish } \\
\text { Time (HEFT) based on resource discovering, filtering, selection, and task } \\
\text { submission }\end{array}$ & 1 & 87 \\
\hline ССР\#8.2 & $\begin{array}{c}\text { Execute part of the application on public cloud to achieve output within } \\
\text { deadline as public cloud resources has much high processing power as } \\
\text { compare to private cloud resources. On the other hand, executing the whole } \\
\text { application on the public cloud will be costly. }\end{array}$ & 4 & 80 \\
\hline ССР\#8.3 & $\begin{array}{l}\text { The capacity of the communication channels in hybrid cloud must be } \\
\text { considered because it impacts the cost of workflow execution. }\end{array}$ & 1 & 97 \\
\hline ССР\#8.4 & $\begin{array}{l}\text { Implement workflow management system like CWMS (Cloud Workflow } \\
\text { Management System) to increase productivity and efficiency }\end{array}$ & 1 & 97 \\
\hline
\end{tabular}




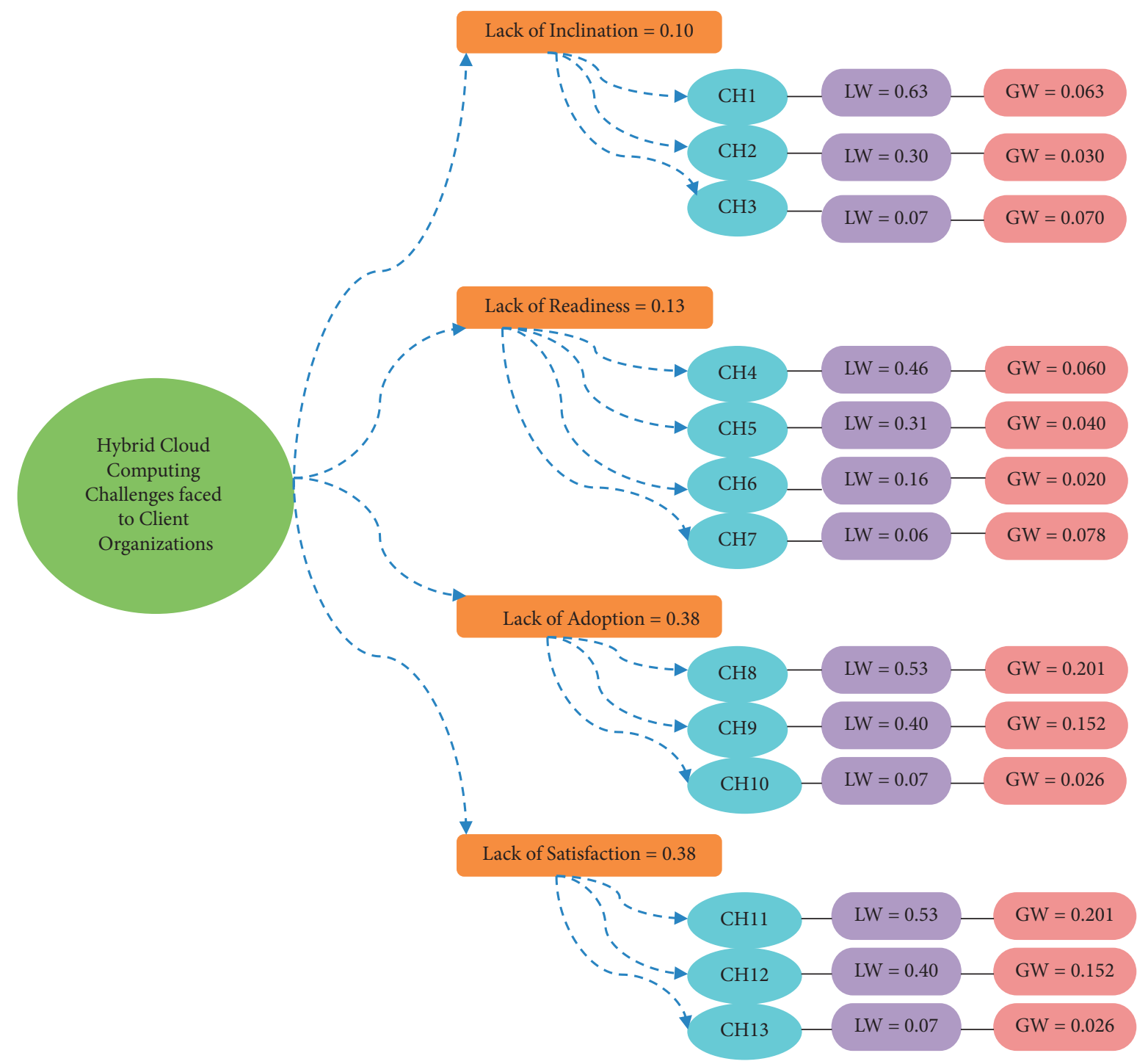

FIGURE 6: Analytical hierarchy process (AHP) based on the prioritization taxonomy of challenging factors with their categories.

TABLE 28: Summary of the research questions.

\begin{tabular}{ll}
$\begin{array}{l}\text { S. } \\
\text { no. }\end{array}$ & Research questions \\
\hline RQ1 & $\begin{array}{l}\text { What are the challenging factors, as described in the literature } \\
\text { and indrial survey, to be avoided by client organizations in } \\
\text { adoption of hybrid cloud computing? }\end{array}$ \\
RQ2 How could the identified challenging factors be prioritized using \\
the AHP approach?
\end{tabular}

What are the practices, as identified in the literature and RQ3 industrial survey, to be followed by vendor organizations to build successful relationship with client organizations in adoption of hybrid cloud computing?

What would be the taxonomy of the identified challenging factors that could assist in the successful relationship between client and vendor organizations in adoption of hybrid cloud computing?
All the challenging factors are presented in Table 4.

AHP approach is followed to prioritize the identified challenging factors. Details are presented in Section 4.4. The summarized list is presented in Table 19.

The practices for the identified challenges are presented in Tables 20-27.

Taxonomy of the identified challenging factors is developed by categorizing these challenges into four main categories, "Lack of Inclination," "Lack of Readiness," "Lack of Adoption," and "Lack of Satisfaction" (Figure 4), and prioritizing them by using the AHP technique. The basic purpose of this taxonomy is to highlight the local weight that shows the priority order of each challenging factor within its category and the global weight to show the effect of a particular challenge on the overall study objective. Furthermore, the taxonomy provides a robust framework that could help practitioners and researchers to handle the major issues of hybrid cloud computing activities. 


\section{Conclusion and Future Work}

We were inspired by the importance of hybrid cloud computing activities to build a taxonomy focused on prioritizing the challenges or challenging factors that could pose risks for hybrid cloud computing adoption by client organizations. The revealed results deliver the key areas which need to be resolved before hybrid cloud computing practices are launched. The SLR1 was performed to classify the challenging factors, and the results of the literature reviews were confirmed by empirical research.

In total, 13 challenges or challenging factors are found via the literature review, and then they are further classified into four main categories: "Lack of Inclination," "Lack of Readiness," "Lack of Adoption," and "Lack of Satisfaction" (Figure 4). In addition, an AHP technique was implemented to prioritize these difficult variables and their groups.

The findings of the AHP technique reveal that "Lack of Adoption" and "Lack of Satisfaction" are the most significant categories and $\mathrm{CH} 8$ (public cloud security concern) and CH11 (achieving QoS) have been considered as the highest-ranking challenging factors, which are also listed in these categories, because of their value GW (0.201), which is found to be higher than the values of all the other challenging factors mentioned.

This study has a knowledge base in the domain of hybrid cloud computing for professionals and academic scholars. On the other hand, in such a field, it also offers state-of-theart work that may be considered as a valuable input to academic studies.

In summary, this study contributes a thorough overview of the perspectives of experts in hybrid cloud computing to illustrate various facets of the field of cloud computing. The future goal of this research work is to produce a robust model that could help client organizations analyze their current capabilities in hybrid cloud computing and include best practices for further improvements.

Our ultimate aim is to develop hybrid cloud adoption assessment model (HCAAM). This paper contributes two components of the HCAAM, i.e., the identification of challenges in the adoption of hybrid cloud and practices for these challenges via SLR and questionnaire survey. The final outcome of the research is the development of HCAAM. The proposed model will be developed based on the results drawn from a systematic review of the literature and survey and will be supported by conducting case studies, which will provide a more comprehensive theoretical and practical assessment of the organization's maturity in the context of hybrid cloud adoption.

\section{Data Availability}

Primary data were collected during the research. The analysis is available in Section 4.3. The tool used for data collection is available in the Supplementary Material, and detailed data can be provided on request.

\section{Disclosure}

The results obtained herein are solely the responsibility of the authors.

\section{Conflicts of Interest}

The authors declare that there are no conflicts of interest regarding the publication of this paper.

\section{Acknowledgments}

The Qatar University Internal Grant No. IRCC-2021-010 funded this publication.

\section{Supplementary Materials}

"AHP Questionnaire Survey" for the questionnaire provided in the manuscript. (Supplementary Materials)

\section{References}

[1] M. Younas, M. A. Shah, D. N. A. Jawawi et al., "Elicitation of nonfunctional requirements in agile development using cloud computing environment," IEEE Access, vol. 8, pp. 209153209162, 2020.

[2] W. Zhao, C. Tian, W. Tian, and Y. Zhang, "Securely and efficiently computing the hermite normal form of integer matrices via cloud computing," IEEE Access, vol. 8, pp. 137616-137630, 2020.

[3] A. Gupta, B. D. Mazumdar, M. Mishra, P. P. Shinde, S. Srivastava, and A. Deepak, "Role of cloud computing in management and education," Materials Today: Proceedings, 2021.

[4] C. Gong, L. Liu, Q. Zhang, H. Chen, and Z. Gong, "The characteristics of cloud computing," in Proceedings of the 39th International Conference on Parallel Processing Workshops, pp. 275-279, San Diego, CA, USA, 2010.

[5] A. A. El-Moursy, F. N. Sibai, H. Khaled, S. M. Nassar, and M. Taher, "Deployment and analysis of a hybrid shared/ distributed-memory parallel visualization tool for 3-D oil reservoir grid on openStack cloud computing," IEEE Access, vol. 8, pp. 212280-212297, 2020.

[6] S. Patidar, D. Rane, and P. Jain, "A survey paper on cloud computing," in Proceedings of the 2012 Second International Conference on Advanced Computing \& Communication Technologies, Rohtak, India, 2012.

[7] K. Annapureddy, Security Challenges in Hybrid Cloud Infrastructures, Aalto University - School of Science and Technology, Espoo, Finland.

[8] j. Peng, X. Zhang, Z. Lei, B. Zhang, Z. Wu, and Q. Li, "Comparison of several cloud computing platforms," in Proceedings of the 2009 Second International Symposium on Information Science and Engineering, Shanghai, China, December 2009.

[9] Z. Mahmood, "Cloud computing: characteristics and deployment approaches," in Proceedings of the 2011 IEEE 11th International Conference on Computer and Information Technology, pp. 121-126, Paphos, Cyprus, Septamber 2011.

[10] S. N. Brohi and M. A. Bamiah, "Challenges and benefits for adopting the paradigm of cloud computing," International Journal of Advanced Engineering Sciences and Technologies, vol. 8, no. 2, pp. 286-290, 2011. 
[11] S. Nawaz Brohi and S. Yoshilkawa, "Fujitsu's approach to hybrid cloud system," Fujitsu Scientific and Technical Journal, vol. 47, no. 3, 2011.

[12] P. Priyadarshinee, K. Jha, D. Raut, M. G. Kharat, and S. S. Kamble, "To identify the critical success factors for cloud computing adoption by MCDM technique," International Journal of Business Information Systems, vol. 24, no. 4, pp. 469-510, 2017.

[13] F. Damanpour and M. Schneider, "Phases of the adoption of innovation in organization: effects of envirnoment, organization and top management," British Journal of Management, vol. 17, no. 3, pp. 215-236, 2006.

[14] P. Priyadarshinee, R. D. Raut, M. K. Jha, and B. B. Gardas, "Understanding and predicting the determinants of cloud computing adoption: a two staged hybrid SEM - neural networks approach," Computers in Human Behavior, vol. 76, pp. 341-362, 2017.

[15] Su. Hu and X. Yinhao, "Design of cloud computing task offloading algorithm based on dynamic multi-objective evolution," Future Generation Computer Systems, vol. 122, pp. 144-148, 2021.

[16] R. B. Hamouda, I. B. Hafaiedh, and R. Robbana, "Modelling and verification of reconfigurable fault-tolerant and self-recovering systems in hybrid Clouds," Simulation Modelling Practice and Theory, vol. 111, Article ID 102331, 2021.

[17] M. A. Obeidat and T. Turgey, "Empirical analysis for the factors affecting the adoption of cloud computing initiatives by information technology executives," Journal of Management Research, vol. 5, no. 1, 2013.

[18] S. U. Khan and N. Ullah, "Challenges in the adoption of hybrid cloud: an exploratory study using systematic literature review," Journal of Engineering, vol. 1, no. 5, pp. 107-118, 2016.

[19] S. Rajan and A. Jairath, "Cloud computing: the fifth generation of computing," in Proceedings of the 011 International Conference on Communication Systems and Network Technologies, Katra, India, June 2011.

[20] J. R. Santos, Security Guidance for Critical Areas of Focus in Cloud Computing v3.0, CSA, Bethesda, Maryland, 2009.

[21] P. Mell and T. Grance, The NIST Definition of Cloud Computing, USA NIST, Gaithersburg, MD, USA, 2011.

[22] D. W. Cearley, Cloud Computing, O'reliy, Sebastopol, CA, USA.

[23] S. Ried, H. Kisker, and P. Matzke, The Evolution of Cloud Computing Markets, Forrester, Cambridge, MA, USA.

[24] S. Subashini and V. Kavitha, "A survey on security issues in service delivery models o fcloud computing," Journal ofNetworkandComputerApplications, vol. 34, pp. 1-11, 2010.

[25] S. Bhardwaj, J. Leena, and S. Jain, "Cloud computing: a study of infrastructure as A service (iaas)," IJEIT, vol. 2, no. 1, pp. 60-63, 2010.

[26] M. Carroll, A. v. d. Merwe, and P. Kotzé, "Secure cloud computing benefits, risks and controls," in Proceedings of the Information Security South Africa (ISSA), Johannesburg, South Africa, Agust 2011.

[27] E. Ristova, V. Gecevska, and Z. Panov, "Hybrid cloud computing challenges and mass customization," in Proceedings of the 5th International Conference on Mass Customization and Personalization in Central Europe, Novi Sad, Serbia, September 2012.

[28] V. Khadilkar, M. Kantarcioglu, B. Thu, and S. Mehrotra, "Secure data processing in a hybrid cloud," 2011, https://arxiv. org/abs/1105.1982.
[29] A. H. Amrohi and A. Kumar, "Benefits of hybrid hosting over conventional hosting," IJCSNS, vol. 13, no. 2, 2013.

[30] P. C. Heckel, Hybrid Clouds: Comparing Cloud Toolkits, University of Mannheim, Mannheim, Germany, 2010.

[31] S. Nepalp, F. Carsten, L. Henry, and S. Chen, "A secure storage service in the hybrid cloud," in Proceedings of the 2011 Fourth IEEE International Conference on Utility and Cloud Computing, Melbourne, Australia, December 2011.

[32] B. Javadi, J. Abawajy, and R. Buyya, "Failure-aware resource provisioning for hybrid Cloud infrastructure," Journal of Parallel and Distributing Computing, vol. 72, pp. 1318-1331, 2012.

[33] S. Tanimoto, Y. Sakurada, Y. Seki et al., "A study of data management in hybrid cloud configuration," in Proceedings of the IEEE 2015 IEEE Twelfth International Symposium on Autonomous Decentralized System (ISADS), Taichung, Taiwan, March 2015.

[34] H. Judith, M. Kaufman, F. Halper, and D. Kirsch, Hybrid Cloud for Dummies, O'reliy, Sebastopol, CA, USA, 2013.

[35] J. Weinman, "Hybrid cloud economics," IEEE Cloud Computing, vol. 3, no. 1, pp. 18-22, 2016.

[36] S. U. Khan, N. Ullah, Challenges in the adoption of hybrid cloud:preliminary results from a systematic literature review," in Proceedings of the 21st Asia-Pacific Software Engineering Conference, Jeju, South Korea, December 2014.

[37] T. Hall, N. Baddoo, S. Beecham, H. Robinson, and H. Sharp, "A Systematic review of theory use in studies investigating the motivations of software engineers," ACM Transactions on Software Engineering and Methodology, vol. 8, 2008 in press.

[38] M. Staples and M. Niazi, "Experiences using systematic review guidelines," Journal of Systems and Software, vol. 80, no. 9, pp. 1425-1437, 2007.

[39] B. Kitchenham and C. Charters, "Guidelines for performing systematic literature reviews in software engineering," Joint Report, Keele University and Durham University, Newcastleunder-Lyme, England, 2007.

[40] C. Wohlin, M. Höst, and K. Henningsson, Empirical Research Methods in Web, Springer, New York, NY, USA, 2003.

[41] S. U. Khan, M. Niazi, and R. Ahmad, "Empirical investigation of success factors for offshore software development outsourcing vendors," Journal of IET Software, vol. 6, no. 1, pp. 1-15, 2012.

[42] R. Khan and S. U. Khan, "Empirical exploration of communication and coordination practices in offshore software development outsourcing," Proceedings of the Pakistan Academy of Sciences, vol. 54, no. 1, pp. 41-54, 2017.

[43] S. U. Khan and M. Niazi, "Critical challenges in offshore software development outsourcing: an empirical study," in Proceedings of the IASTED International Conference on Software Engineering, Innsbruck, Austria, February 2013.

[44] T. L. Saaty, "Analytic hierarchy process," in Encyclopedia of Operations Research and Management Science, S. I. Gass and C. M. Harris, Eds., pp. 19-28, Springer, New York, NY, USA, 2001.

[45] M. Shameem, R. R. Kumar, C. Kumar, B. Chandra, and A. A. Khan, "Prioritizing challenges of agile process in distributed software development environment using analytic hierarchy process," Journal of Software: Evolution and Process, vol. 30, no. 11, p. e1979, 2018.

[46] I. Palcic, "Analytical Hierarchy Process as a tool for selecting and evaluating projects," International Journal of Simulation Modelling, vol. 8, pp. 16-26, 2009.

[47] F. T. Bozbura, A. Beskese, and C. Kahraman, "Prioritization of human capital measurement indicators using fuzzy AHP," 
Expert Systems with Applications, vol. 32, no. 4, pp. 1100-1112, 2007.

[48] F. T. S. Chan and N. Kumar, "Global supplier development considering risk factors using fuzzy extended AHP-based approach,” Omega, vol. 35, no. 4, pp. 417-431, 2007.

[49] S. Soh, "A decision model for evaluating third-party logistics providers using fuzzy analytic hierarchy process," African Journal of Business Management, vol. 4, pp. 339-349, 2010.

[50] A. W. Khan, I. Hussain, and M. Zamir, "Analytic hierarchy process-based prioritization framework for vendor's reliability challenges in global software development," Journal of Software: Evolution and Process, vol. 33, no. 2, p. e2310, 2020.

[51] M. A. Akbar, A. A. Khan, A. W. Khan, and S. Mahmood, "Requirement change management challenges in GSD: an analytical hierarchy process approach," Journal of Software: Evolution and Process, vol. 32, no. 7, p. e2246, 2020.

[52] G. Kabra, A. Ramesh, and K. Arshinder, "Identification and prioritization of coordination barriers in humanitarian supply chain management," International Journal of Disaster Risk Reduction, vol. 13, pp. 128-138, 2015.

[53] P. Goyal, "Enterprise usability of cloud computing environments: issues and challenges," pp. 54-59.

[54] J. Li, Y. K. Li, X. Chen, P. P. C. Lee, and W. Lou, "A hybrid cloud approach for secure authorized deduplication," IEEE Transactions on Parallel and Distributed Systems, vol. 26, no. 5, pp. 1206-1216, 2015.

[55] R. Balasubramanian and A. Murugaiyan, "Security issues: public vs private vs hybrid cloud computing," International Journal of Computer Application, vol. 55, pp. 35-41, 2012.

[56] W. Wang, L. Chen, and Q. Zhang, "Outsourcing high-dimensional healthcare data to cloud with personalized privacy preservation," Computer Networks, vol. 88, pp. 136-148, 2015.

[57] S. Yan, C. Chen, G. Zhao, and B. S. Lee, "Cloud service recommendation and selection for enterprises," in Proceedings of the Network and service management (cnsm), 2012 8th international conference and 2012 workshop on systems virtualiztion management (svm), pp. 430-434, Las Vegas, NV, USA, October 2012.

[58] R. Bhadauria, R. Chaki, N. Chaki, and S. Sanyal, "A survey on security issues in cloud computing," 2011, https://arxiv.org/ abs/1109.5388.

[59] N. Leavitt, "Hybrid clouds move to the forefront," Computer, vol. 46, pp. 15-18, 2013.

[60] B. Javadi, J. Abawajy, and R. O. Sinnott, "Hybrid Cloud resource provisioning policy in the presence of resource failures," in Proceedings of the 2012 IEEE 4th International Conference onCloud Computing Technology and Science (CloudCom), pp. 10-17, Taipei, Taiwan, December 2012.

[61] W. Z. Jiang and Z. Q. Sheng, "A New task scheduling algorithm in hybrid cloud environment," in Proceedings of the 2012 International Conference on Cloud and Service Computing, pp. 45-49, Shanghai, China, January 2012.

[62] J. Abawajy, "Establishing trust in hybrid cloud computing environments," in Proceedings of the 2011IEEE 10th International Conference on Trust, Security and Privacy in Computing and Communications, pp. 118-125, Changsha, China, November 2011.

[63] T. H. Noor, Q. Z. Sheng, S. Zeadally, and J. Yu, "Trust management of services in cloud environments: obstacles and solutions," ACM Computing Surveys, vol. 46, no. 1, p. 12, 2013.

[64] M. Hussain, H. U. Khan, A. W. Khan, and S. U. Khan, "Prioritizing the issues extracted for getting right people on right project in software project management from vendors' perspective," IEEE Access, vol. 9, pp. 8718-8732, 2021.
[65] M. Niazi, S. Mahmood, M. Alshayeb et al., "Challenges of project management in global software development: a clientvendor analysis," Information and Software Technology, vol. 80, pp. 1-19, 2016.

[66] M. Niazi, S. Mahmood, M. Alshayeb, A. M. Qureshi, K. Faisal, and N. Cerpa, "Toward successful project management in global software development," International Journal of Project Management, vol. 34, no. 8, pp. 1553-1567, 2016. 